\title{
Surgical membranectomy with modified incision and capsulotomy microscissors for persistent pupillary membrane
}

\author{
Huiling Hü, Danyao Nie", Yunyun Zou, Bing Du, Min Fang, Mingmin Yang, Jiantao Wang*, Xinhua Liu* \\ Shenzhen Eye Hospital, Shenzhen Eye Hospital affiliated to Jinan University, School of Optometry, Shenzhen University, Shenzhen, China \\ Contributions: (I) Conception and design: H Hu, D Nie; (II) Administrative support: X Liu, J Wang; (III) Provision of study materials or patients: \\ B Du, X Liu; (IV) Collection and assembly of data: H Hu, D Nie, Y Zou; (V) Data analysis and interpretation: M Fang, M Yang; (VI) Manuscript \\ writing: All authors; (VII) Final approval of manuscript: All authors. \\ \#These authors contributed equally to this work. \\ *These authors contributed equally to this work. \\ Correspondence to: Jiantao Wang; Xinhua Liu. Shenzhen Eye Hospital,18\#Zetian Road, Shenzhen 518000, China. \\ Email: wangjiantao65@126.com; xhualiu@sohu.com.
}

\begin{abstract}
Background: To evaluate the visual outcome and complications of surgical membranectomy with modified incision and capsulotomy microscissors in patients with persistent pupillary membrane (PPM).

Methods: We enrolled eight eyes with PPM in six patients and performed surgical membranectomy with modified incision located near the limbus and corresponding to the middle of the densest membrane strands. Strands near the collarette of the iris were then cut using capsulotomy microscissors and thick strands were removed with capculorhexis forceps. Complications during or after surgery were evaluated, and uncorrected visual acuity (UCVA) and best corrected visual acuity (BCVA) were compared pre- and post-surgery.

Results: The mean age of the patients at surgery was 9.5 \pm 3.4 years (range, 5.3 to 13.8 years). Bilateral PPMs were found in two patients, small anterior capsular cataracts not locating on the visual axis in three eyes, and deprivational amblyopia in four eyes. There were no traumatic cataracts, endophthalmitis, corneal opacities, or other complications in patients during or after modified surgical membranectomy. After a mean follow-up period of $5.8 \pm 0.4$ (range, 5.0 to 6.0) months, UCVA was significantly improved from $0.23 \pm 0.14$ to $0.36 \pm 0.20(\mathrm{P}=0.026)$, and BCVA was also significantly improved from $0.32 \pm 0.22$ pre-operatively to $0.56 \pm 0.25$ post-operatively $(\mathrm{P}=0.006)$.
\end{abstract}

Conclusions: Surgical membranectomy with modified incision and capsulotomy microscissors may be a safe approach to clear the visual axis of patients with PPM. However further treatments were needed in amblyopic eyes after surgery.

Keywords: Membranectomy; persistent pupillary membrane; modified incision; capsulotomy microscissors

Submitted Apr 02, 2021. Accepted for publication May 21, 2021.

doi: 10.21037/apm-21-995

View this article at: http://dx.doi.org/10.21037/apm-21-995

\section{Introduction}

A persistent pupillary membrane (PPM) is a remnant of the tunica vasculosa lentis, which is the blood supply for the lens epithelium during fetal life $(1,2)$. PPM appears as fine iris strands along the pupil and can be seen in $95 \%$ of neonates and $20 \%$ of adult population (3). While PPMs not affecting vision are common and require no treatment
$(4,5)$, dense membrane can hinder vision development as less than $1.5 \mathrm{~mm}$ pupillary apertures may obscure light to the retina and occlude visual axis $(6,7)$. To reduce the risk of deprivational amblyopia for these patients, early surgical intervention should be considered (8).

Surgical membranectomy has been employed in patients with thick or dense PPM in previous studies. However, traumatic iatrogenic cataract could be induced if the 

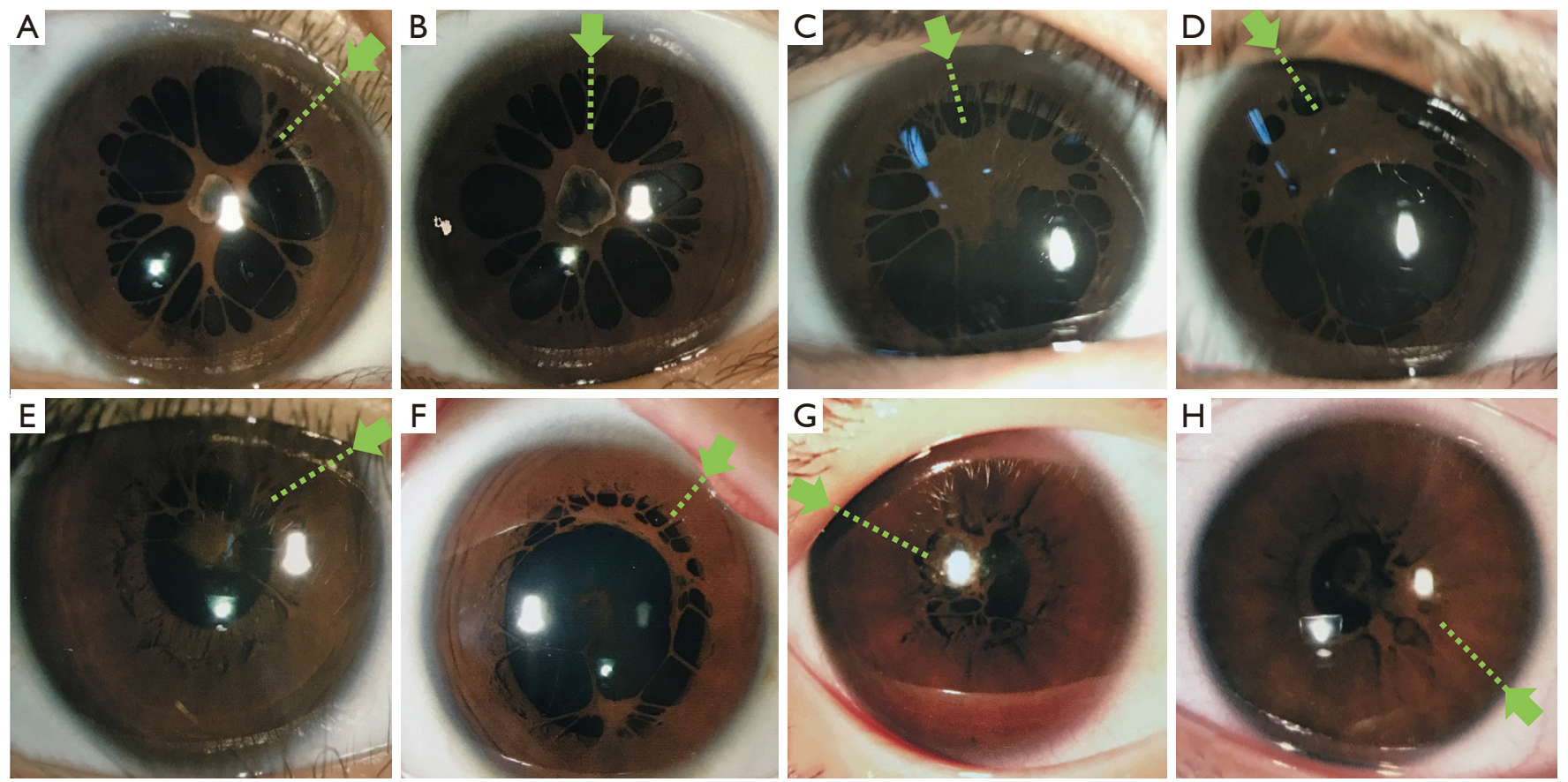

Figure 1 Modified incision position for PPM surgical membranectomy. (A-H)Anterior segment imaging of eyes 1-8. The position of corneal tunnel incisions is shown by green arrows located near the limbus and corresponding to the middle of the densest membrane strands. PPM, persistent pupillary membrane.

lens is accidentally damaged $(9,10)$. To reduce the risk of complications, membranectomy with modified incision and capsulotomy microscissors was performed and the surgical outcome was evaluated. We present the following article in accordance with the STROBE reporting checklist (available at http://dx.doi.org/10.21037/apm-21-995).

\section{Methods}

The study was approved by the Medical Ethics Committee of Shenzhen Eye Hospital (Number: 20201230-04) and adhered to the provisions of the Declaration of Helsinki (as revised in 2013) for research involving human subjects. All patients involved gave written informed consent by their parents or guardians after discussion of the potential benefits and risks of surgical membranectomy.

This study enrolled eight eyes (six patients) with thick or dense PPM from who presented between February 2015andJune 2018to the Shenzhen Eye Hospital. PPM was diagnosed as a thick membrane covering the pupil and attached to the iris collarette. Indications for surgical membranectomy included decreased visual acuity, poor red reflex from retinoscopy, or impaired fundus visualization.
Sequential surgery was performed in bilateral PPM cases with the thicker membrane removed first.

The main outcome measures included slit-lampassisted biomicroscopy (Haag-Streit, Koeniz, Switzerland), intraocular pressure (IOP), uncorrected visual acuity (UCVA), and best corrected visual acuity (BCVA) using a logMAR chart. All subjects underwent a broad ophthalmologic examination at baseline and the follow-up visit.

The same surgeon performed the surgical procedure for all eyes in this study following the Gregg T. Lueder's technique with modification (11). The operations were performed under general anesthesia, and Tropicamide eye drops were placed prior to surgery for pupil dilation. The anterior chamber was entered using a $3.0 \mathrm{~mm}$ keratome via a modified corneal tunnel incision located near the limbus and corresponding to the middle of the densest membrane strands (Figure 1).

A high-viscosity viscoelastic material (Pe-Ha-Luron F, ALBOMED, Schwarzenbruck, Germany) was then injected into the anterior chamber which then went behind the central iris adhesion to lift the $\operatorname{PPM}($ Figure $2 A)$. Care was taken to avoid touching the lens anterior capsule, and 

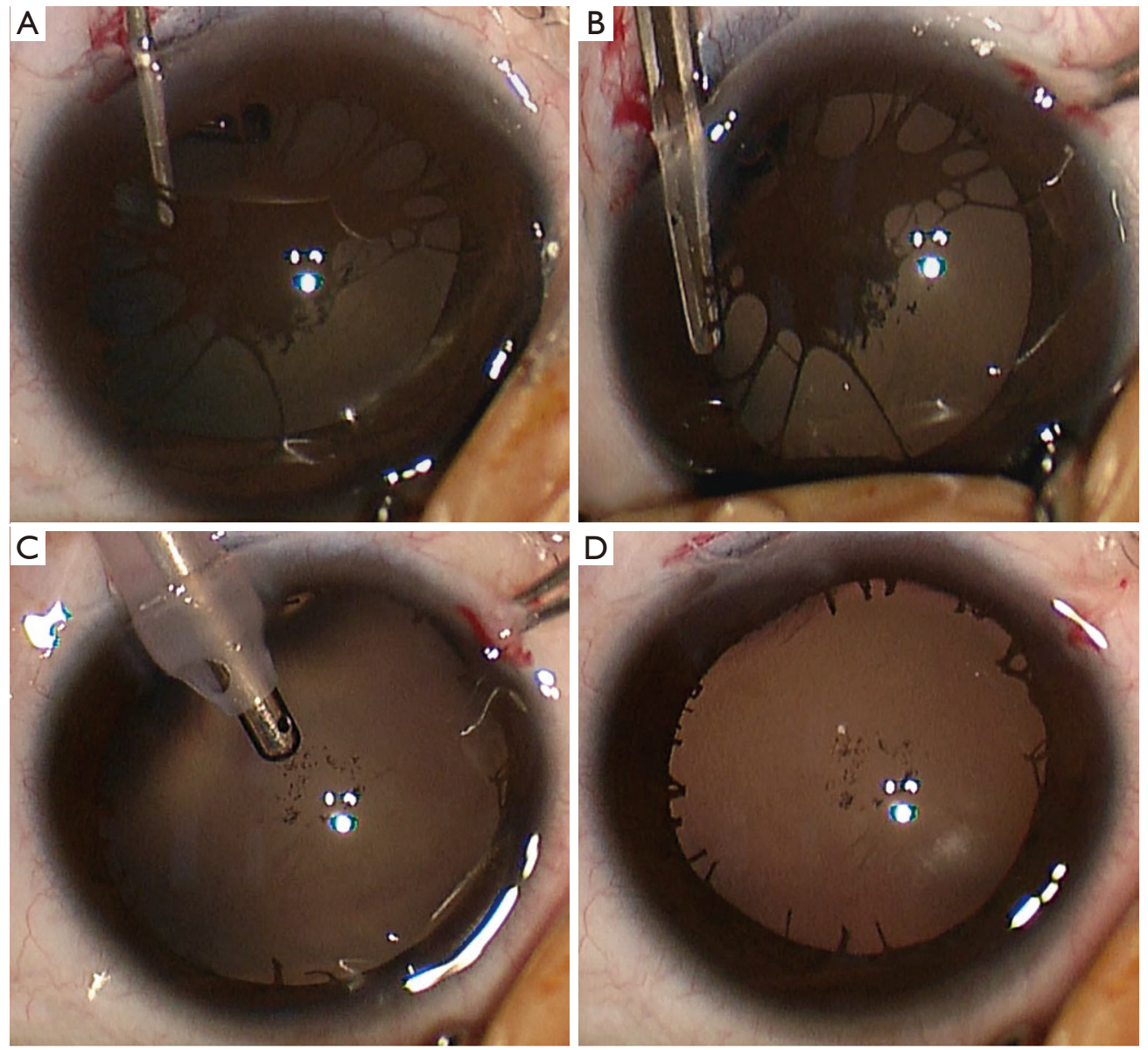

Figure 2 Surgical membranectomy procedure for eye 3 with modified incision and capsulotomy microscissors. (A) Through a modified corneal incision, the PPM was separated using high-viscosity viscoelastic material. (B) PPM was cut using capsulotomy microscissors. (C) Residual strands were removed by irrigation and aspiration. (D) Anterior chamber was inflated by injecting sterile balanced salt solution. PPM, persistent pupillary membrane.

additional viscoelastic was injected beneath the strands after the central iris adhesions were lysed. Strands near the collarette of the iris were then cut using capsulotomy microscissors (Hoffer-Stern Scissors, Stephens Instruments, Lexington, KY, USA) (Figure 2B) and thick strands were removed with capculorhexis forceps. Residual small floating strands and viscoelastic were removed completely by an automated irrigation and aspiration apparatus (Alcon Laboratories Inc., Fort Worth, TX, USA) (Figure 2C). The corneal incision was hydrated with sterile balanced salt solution (Figure 2D), then required a single 10-0 nylon suture (Alcon Laboratories Inc., Fort Worth, TX, USA) which was removed one month postoperatively.

Postoperative medications included topical $0.5 \%$ levofloxacin eyedrops four times daily, $1 \%$ prednisolone acetate ophthalmic suspension four times daily, and tobramycin/dexamethasone ointment once a day tapered over 3-4 weeks. Postoperative examinations were performed 1 day, 1 week, 1 month, and 6 months after surgery. Postoperative complications, including cataract, bleeding, and inflammation, were observed for, and visual acuity, IOP, pupil size, pupil shape, and reactivity were also assessed.

Statistical Analysis

Statistical analysis was performed using SPSS (Statistical Package for the Social Sciences, IBM, Armonk, New York, Ver. 25) and the means \pm standard deviations of all the main parameters were analyzed. $T$ test was used to compare the differences between pre- and post-operative groups and $\mathrm{P}$ 
Table 1 Clinical characteristics of patients with PPM

\begin{tabular}{lccccc}
\hline Patient No. & Sex & Age (years) & Eye No. & PPM eye & Other diagnosis \\
\hline 1 & M & 7 & 1 & OD & Amblyopia \\
2 & M & 5 & 2 & OS & Anterior capsular cataract \\
& & & 3 & OD & Anterior capsular cataract \\
4 & M & 14 & 4 & OD & Amblyopia \\
5 & M & 13 & 5 & OD & Anterior capsular cataract \\
6 & M & 10 & 6 & OD & Amblyopia \\
\hline
\end{tabular}

PPM, persistent pupillary membrane; M, male; F, female; OD, right eye; OS, left eye; OU, both eyes.

values $<0.05$ were considered statistically significant.

\section{Results}

As shown in Table 1, a total of eight eyes of six patients (five males) were included in this study. The mean age at surgery was $9.5 \pm 3.4$ years (range, 5.3 to 13.8 years).

Bilateral PPMs were found in two patients, small anterior capsular cataracts not locating on the visual axis in three eyes, and deprivational amblyopia in four eyes. There were no traumatic cataracts, endophthalmitis, corneal opacities, or other complications in patients during or after modified membranectomy. The depth of the anterior chamber and IOP were within normal limits. Figure $3 A, B$ show postoperative anterior segment imaging of eyes 3 and 7 one day after surgery. The membrane had been completely removed and the pupil is $3 \mathrm{~mm} \times 3 \mathrm{~mm}$ round. In eye 3 , small clumps of anterior lens capsule pigmentation are seen (Figure $3 A$ ).

After a mean follow-up period of $5.8 \pm 0.4$ (range, 5.0 to 6.0) months, post-operative UCVA improved in six eyes, BCVA improved in seven (Figure 3C,D), and the mean visual acuity of patients was significantly improved. UCVA was $0.23 \pm 0.14$ (range, 0.04 to 0.4 ) at baseline and was $0.36 \pm 0.20$ (range, 0.05 to 0.6$)$ at the final visit $(\mathrm{P}=0.026$, paired $t$-test). Before surgery, BCVA was $0.32 \pm 0.22$ (range, 0.04 to 0.6 ) and at the final visit this was $0.56 \pm 0.25$ (range, 0.05 to 0.8 ) $(\mathrm{P}=0.006)$.

\section{Discussion}

The management of PPM depends on the embrane extent and papillary opening size. Small PPM can be observed only or treated by topical mydriatic agents $(4,12)$. While membranectomy by Nd:YAG laser or Argon laser has been successfully employed in older patients with thick PPM (13-15), it is technically difficult in children and carries a risk of hyphema (16), cataract formation, and pigment dispersion $(14,15)$. High-viscosity viscoelastic protected membranectomy represents an effective approach in dense and thick PPM (11,17-21). Different incisions and surgical instruments have been applied in previous studies (Table 2), with the risk of developing traumatic iatrogenic cataract the most important surgery complication $(9,10)$.

To minimize this risk, we modified the position of corneal tunnel incision near the limbus corresponding to the middle of the densest membrane strands. The modified incision has several advantages. First, it shortens the distance for the viscoelastic needle, lifting dense membrane away from the crystalline lens. Second, the risk of surgical instruments going through the central pupil zone is reduced, and third, the incision is much closer to the iris collarette, providing an optimum angle for the iris strands cut.

In this study, capsulotomy microscissors were applied in the surgery. The blunt tips and curved thinning blade of this instrument protects the lens against damage, while the $11 \mathrm{~mm}$ cutting length of the blades avoids repeated moving and cutting at the limited space of the anterior chamber. Further, the automated irrigation and aspiration apparatus, which was applied to remove the residual strands and viscoelastic, provided a more stable anterior chamber and less damage to the angle structure (22). After membranectomy, only one single suture was needed in our technique as the incision was only $3.0 \mathrm{~mm}$, through which surgically induced astigmatism was reduced. 

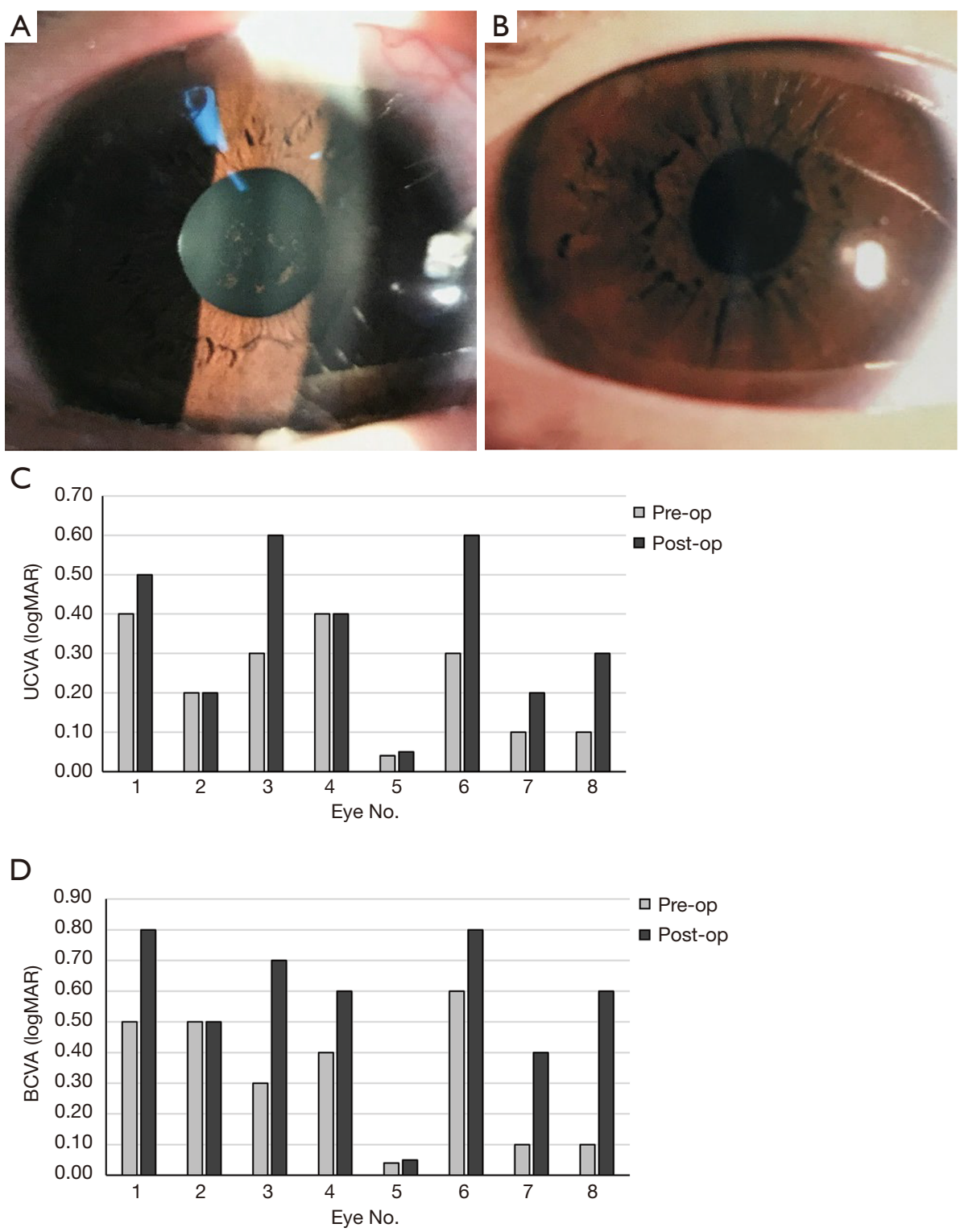

Figure 3 Post-operative anterior segment imaging and visual acuity comparison. (A) Post-operative anterior segment imaging of eye 3. (B) Post-operative anterior segment imaging of eye 7. (C) Pre- and post-operative UCVA of each eye. (D) Pre- and post-operative BCVA of each eye. UCVA, uncorrected visual acuity; BCVA, best corrected visual acuity; Pre-oP, pre-operative; Post-oP, post-operative.

There were no intra- or post-operative complications of the modified membranectomy procedure during the followup period in this study, although in eye 3 , small clumps of anterior lens capsule pigmentation presented during and after surgery, which may be due to posterior synechia of PPM and was not considered to be a complication.

In our study, the BCVA at baseline of patients with PPM was only $0.32 \pm 0.08$, possibly due to the low retinal illumination caused by a small pupil (23), and while post- operative BCVA improved in seven eyes, it remained lower than normal for the age of patients. Further treatments, such as eye patching and refractive correction were still needed in amblyopic eyes, which were present in four of the eight eyes prior to surgery. Patients with amblyopic eyes in this study came from rural areas and did not undertake routine eye examinations. Children with PPM should be evaluated for the risk of amblyopia at an early stage, especially in monocular cases, to ensure the appropriate 


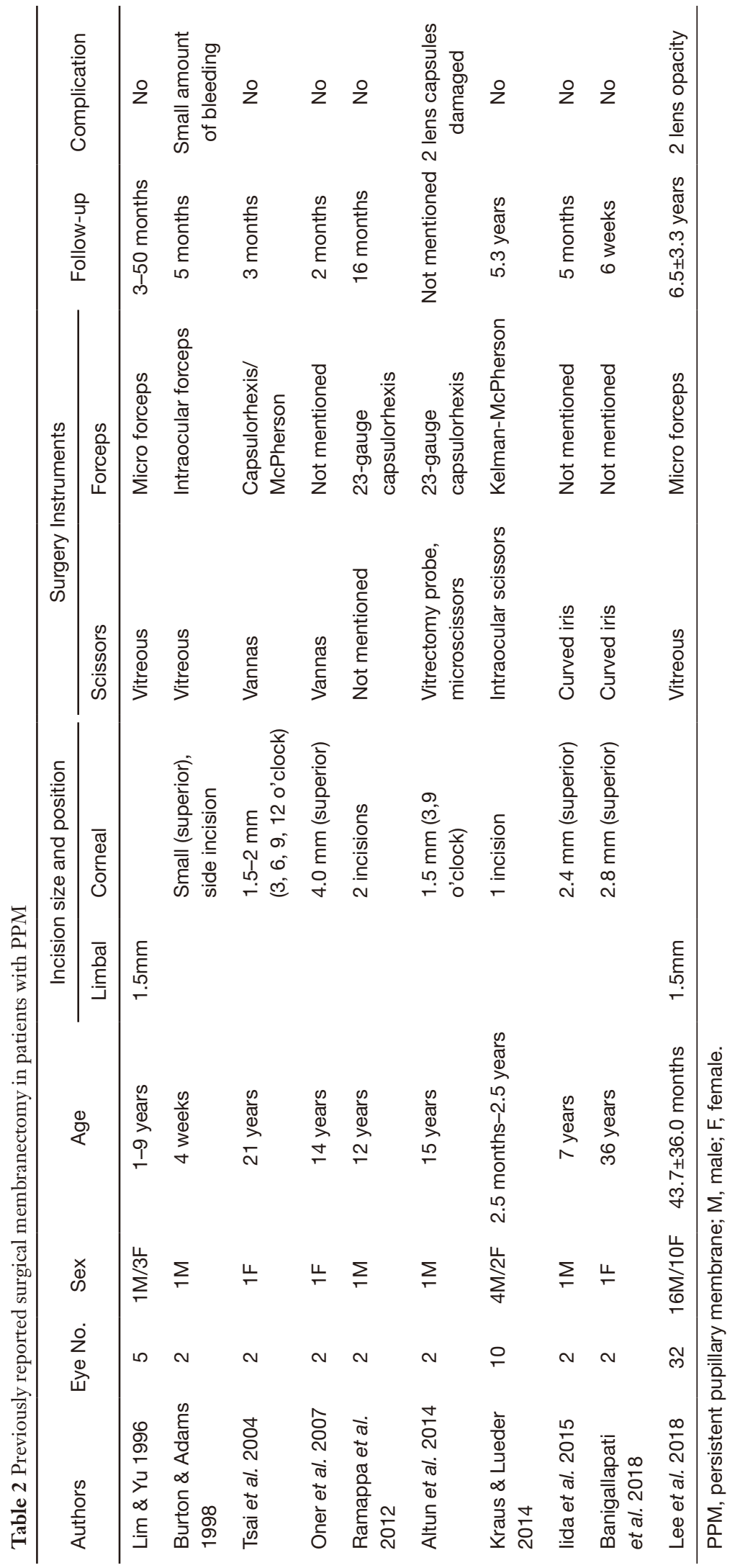


intervention to maintain visual acuity is provided.

The limitations to this study are its the short follow-up period and small sample size, which is due to the rarity of thick or dense PPM.

\section{Conclusions}

Surgical membranectomy with modified incision and capsulotomy microscissors may be one of the safest and most effective approaches to clear the visual axis with a low risk of complication. However, further treatment is needed in amblyopic eyes after surgery.

\section{Acknowledgments}

Funding: This work was supported by the Shenzhen San Ming Project (SZSM201812091), Shenzhen, China and Medical Scientific Research Foundation of Guangdong Province of China (B2021216).

\section{Footnote}

Reporting Checklist: The authors have completed the STROBE reporting checklist. Available at http://dx.doi. org/10.21037/apm-21-995

Data Sharing Statement: Available at http://dx.doi. org/10.21037/apm-21-995

Conflicts of Interest: All authors have completed the ICMJE uniform disclosure form (available at http://dx.doi. org/10.21037/apm-21-995). The authors have no conflicts of interest to declare.

Ethical Statement: The authors are accountable for all aspects of the work in ensuring that questions related to the accuracy or integrity of any part of the work are appropriately investigated and resolved. The study was approved by the Medical Ethics Committee of Shenzhen Eye Hospital (Number: 20201230-04) and adhered to the provisions of the Declaration of Helsinki (as revised in 2013) for research involving human subjects. All patients involved gave written informed consent by their parents or guardians after discussion of the potential benefits and risks of surgical membranectomy.

Open Access Statement: This is an Open Access article distributed in accordance with the Creative Commons
Attribution-NonCommercial-NoDerivs 4.0 International License (CC BY-NC-ND 4.0), which permits the noncommercial replication and distribution of the article with the strict proviso that no changes or edits are made and the original work is properly cited (including links to both the formal publication through the relevant DOI and the license). See: https://creativecommons.org/licenses/by-nc-nd/4.0/.

\section{References}

1. Kadomoto S, Uji A, Tsujikawa A. Anterior Segment Optical Coherence Tomography Angiography in a Patient With Persistent Pupillary Membrane. JAMA Ophthalmol 2018;136:e182932.

2. Merin S, Crawford JS, Cardarelli J. Hyperplastic persistent pupillary membrane. Am J Ophthalmol 1971;72:717-9.

3. Tasman W JE. Duane's Ophthalmology. Philadelphia: Lippincott Williams \& Wilkins, 2007:248-58.

4. Gokhale V, Agarkar S. Persistent Pupillary Membrane. N Engl J Med 2017;376:561.

5. Norris JH, Backhouse OC. The congenital pinhole: a persistent pupillary membrane. Clin Exp Optom 2010;93:100-1.

6. Banigallapati S, Potti S, Marthala H. A rare case of persistent pupillary membrane: Case-based approach and management. Indian J Ophthalmol 2018;66:1480-3.

7. Rubin ML. Quantification on the pinhold effect. Surv Ophthalmol 1977;21:347-50.

8. Birch EE, Stager DR. The critical period for surgical treatment of dense congenital unilateral cataract. Invest Ophthalmol Vis Sci 1996;37:1532-8.

9. Lee HJ, Kim JH, Kim SJ, et al. Long-term Lens Complications Following Removal of Persistent Pupillary Membrane. Korean J Ophthalmol 2018;32:103-7.

10. Altun A, Kurna SA, Bozkurt E et al. Bilateral persistent pupillary membrane with tetralogy of fallot: a case report and review of the literature. Case Rep Ophthalmol Med 2014;2014:581273.

11. Kraus CL, Lueder GT. Clinical characteristics and surgical approach to visually significant persistent pupillary membranes. J AAPOS 2014;18:596-9.

12. Shlamovitz GZ, Reardon PC. Images in clinical medicine. Persistent pupillary strands and membranes. N Engl J Med 2010;362:1325.

13. Wang JK, Wu CY, Lai PC. Sequential argon-YAG laser membranectomy and phacoemulsification for treatment of persistent pupillary membrane and associated cataract. J Cataract Refract Surg 2005;31:1661-3. 
14. Gupta R, Kumar S, Sonika, Sood S. Laser and surgical management of hyperplastic persistent pupillary membrane. Ophthalmic Surg Lasers Imaging 2003;34:136-9.

15. Mansour AM, Hamade I, Antonios RS. Sequential argon-YAG laser membranotomy of extensive persistent pupillary membrane with visual loss. BMJ Case Rep 2015;2015:bcr2015210140.

16. Kapoor KG, Baratz KH, Barkmeier AJ. Laser photocoagulation of an avulsed persistent pupillary membrane vessel causing recurrent hyphaema. Clin Exp Ophthalmol 2013;41:513-5.

17. Tsai YY, Chiang CC, Tsai CH. Surgical technique for removing an extensive persistent pupillary membrane. J Cataract Refract Surg 2004;30:1622-5.

18. Mikhail M, Modabber M, Khan A. Surgical management of anterior capsular plaque associated with persistent pupillary membranes. Eye (Lond) 2016;30:1274-5.

Cite this article as: $\mathrm{Hu} \mathrm{H}$, Nie D, Zou Y, Du B, Fang M, Yang M, Wang J, Liu X. Surgical membranectomy with modified incision and capsulotomy microscissors for persistent pupillary membrane. Ann Palliat Med 2021;10(5):5619-5626. doi: 10.21037/ apm-21-995
19. Burton BJ, Adams GG. Persistent pupillary membranes. Br J Ophthalmol 1998;82:711-2.

20. Oner A, Ilhan O, Dogan H. Bilateral extensive persistent pupillary membranes. J Pediatr Ophthalmol Strabismus 2007;44:57-8.

21. Ramappa M, Murthy SI, Chaurasia S et al. Lenspreserving excision of congenital hyperplastic pupillary membranes with clinicopathological correlation. J AAPOS 2012;16:201-3.

22. Abouali O, Bayatpour D, Ghaffariyeh A, et al. Simulation of flow field during irrigation/aspiration in phacoemulsification using computational fluid dynamics. J Cataract Refract Surg 2011;37:1530-8.

23. Miller SD, Judisch GF. Persistent pupillary membrane: successful medical management. Arch Ophthalmol 1979;97:1911-3.

(English Language Editor: B. Draper) 